\title{
Predictive Control of Switched Reluctance Motors for Aircraft Electrical Actuators Applications
}

\author{
Reyad Abdel-Fadil ${ }^{1,2}$, László Számel ${ }^{1}$ \\ ${ }^{1}$ Budapest University of Technology and Economics, Department of Electric \\ Power Engineering, Egry József u. 18, H-1111 Budapest, Hungary \\ ${ }^{2}$ Aswan University, Electrical Engineering Department, Abu El-Reish Qebly, \\ Aswan Faculty of Engineering st., 81542 Aswan, Egypt \\ Reyad.abdelfadil@aswu.edu.eg, szamel.laszlo@vet.bme.hu
}

\begin{abstract}
Aircraft applications require high reliability, high availability, and high power density, while aiming to decrease weight, complexity, fuel consumption, operational costs, and environmental impacts. Modern electric driving systems can meet these demands and provide significant technical and economic enhancements over traditional mechanical, hydraulic, or pneumatic systems. Due to the high reliability of Switched Reluctance Motors (SRMs), it can be used for aircraft electromechanical actuators to replace the conventional actuators. This paper presents Model Predictive Control (MPC) for the actuators system to drive flight control surfaces in modern civil aircraft. In this study, the actuators system with nonlinear SRM is modeled, simulated, and controlled using a predictive control technique. The predictive control algorithm is applied for a three-phase controlled rectifier to provides a fixed DC voltage for actuators supply bus, and for SRM's symmetrical power converter to drive the surface of the actuator. The performance of the proposed system is tested using a simulation model in PSIM software, and the controller is programmed using $C$ language. Obtained results confirm the effectiveness of the suggested system to drive aircraft electromechanical actuators satisfactorily for either tracking demanded motor speed or desired actuator deflection angle.
\end{abstract}

Keywords: Switched Reluctance Motor; Model Predictive Control; Current Control; More Electric Aircraft; Aircraft Electrical Actuators

\section{Introduction}

In recent years, electrically powered equipment in the aerospace industry is increasing, these types of aircraft referred to as "More Electric Aircraft" (MEA) [1-3]. Although this trend has many benefits such as reliability, aviation safety, efficiency, and improved aircraft maintenance capability, it faces some challenges that must be overcome such as power supply for high-power electrical equipment 
and high-performance motors for electric actuation systems, and power converters with high accuracy controllers. Aircraft actuators are used to control the aircraft during take-off, flight, landing, and taxis by moving the flight control surfaces (rudder, aileron, and spoiler). The flight control surfaces actuators of the conventional civil aircraft are powered through three independent hydraulic systems, that are considered complex to install and costly to maintain. Therefore, modern aircraft use high-power electrical actuators with ratings of up to $50 \mathrm{~kW}$ to solve the hydraulic system's problems [4], and the concept of replacing the hydraulic systems with electrical systems has been associated with MEA concept. Previous and recent studies and research have confirmed that MEA provides aircraft manufacturers and operators with significant cost benefits due to reductions in system complexity and overall weight of the aircraft [5]. The flight actuators can be divided into two main technologies: the first is Fly-By-Wire (FBW) in this technology, actuators are powered hydraulically but controlled by electrical signals. The second is Power-By-Wire (PBW), where the flight actuators are powered and controlled using electrical power [1].

The control surfaces of large conventional civil aircraft such as Airbus (A320) and Boeing (B777) are hydraulically actuated, and most of these actuators are controlled by an electrical signal (FBW technology). But hydraulic systems are expensive, and their weight contributes to most fuel consumption. Therefore, many research and development activities have proposed various systems and components as a solution to replace hydraulic power with electric power aims to reduce the overall weight of the system, reduce complexity, and increase efficiency. Recently, with the developments in high-performance motors, power electronics devices, and control techniques, the use of electrically powered actuators (PBW technology) has gradually increased in civil aircraft. Electrically powered actuators can be divided into two main configurations: the first is Electro-Hydrostatic Actuator (EHA) with fluidic gearing between the motor and the actuated surface, the second is the Electro-Mechanical Actuator (EMA) with mechanical gearing [6], the EHA and EMA configurations will be discussed in Sections 2.

Electric actuators system can be operated efficiently by using high-performance electric motors with a suitable power converter and optimal control strategy. There are many types of electric motors that can be used to drive the flight control actuators such as DC motor which introduced in [7, 8]. Recently, the researches tended to use different types of electric motors with the application of advanced control strategies to reduce the cost, overcome the disadvantages of traditional methods, and improve the overall performance. One of these motors is the Switched Reluctance Motor (SRM) because it has several advantages such as simple construction and material composition, high starting torque, high-speed ranges, higher reliability, low inertia, and the low manufacturing cost $[9,10]$. But the most significant challenges to be overcome if using SRM are the problem of torque ripples and the complexity of the control. The main idea of the SRM is that 
the phase currents are switched ON and OFF according to the rotor position data, by sequential currents that switching into the motor windings, the rotor rotates to align itself with the minimum reluctance position, because of this movement the torque will be generated $[11,12]$.

Generally, the current controller of SRMs can be implemented by using the Hysteresis Current Control (HCC) method with high switching frequencies electronics elements or by using the Pulse Width Modulation (PWM) method. The main advantages of HCC are robustness and easy to implement with analog elements, but on the other hand, it causes a residual current ripple. Regarding the PWM controller, although this method needs a modulator to calculate ON and OFF times, the switching frequency will be known and controllable. In this study the Model Predictive Control (MPC) is used for the current controller, this method directly generates the switching signals for the converter switches without the need for a modulator. Predictive control technique uses the system model to predict the future values of control variables, the predicted values are applied to the control unit to determine the best performance possible based on pre-defined criteria [13].

The most important advantages of predictive control are that it depends on the system itself to generate the controller equation, and with predictive control help, the controller's cascaded structure can be avoided to achieve high-performance and rapid transient response [14]. Also, this control strategy is an ideal strategy for motor drives applications because of robustness, flexibility, and ease of understanding [15-19]. However, the MPC faces some difficulties such as the need for large memory size to store calculated data and comparisons between different actions to determine the optimal procedure. Also, this type of control is highly sensitive to any changes in system parameters, especially parameters that are used directly in prediction equations. In addition, the MPC typically operates at high switching frequencies which leads to high switching losses [20]. Also, in case of including more than objective in the cost function equation of the MPC, the weighting factors of the objectives must be optimized according to the desired performance, and the optimization method must be selected carefully to achieve the best performance. several models of optimal control have been introduced which can contribute to optimizing the controller objectives [21-24].

This work aims to contribute to increasing the use of the SRM in electric vehicles, especially in more electric aircraft's applications, by utilizing these motors to drive the aircraft's flight control surfaces actuators, due to the several advantages of the SRM. Meanwhile, this work tried to overcome the operation problem of the SRM, such as torque ripples, by using advanced control techniques (MPC) to reduce the torque ripples, taking into consideration optimization of the average switching frequency and the maximum stator current to reduce the system losses. 


\section{Aircraft Electrically Powered Actuators}

\subsection{Electro-Mechanical Actuator (EMA)}

The configuration of the EMA is shown in Fig. 1, and this type of actuators can be used to drive the inboard spoiler surfaces of aircraft. The bi-directional power converter is used in this type of electric actuators to supply the motor with demanded power, this power is utilized to moves the spoiler surface through a mechanical transmission with a gearbox, and a ball-screw mechanism. Regarding the control unit, as can be seen from the actuator configuration diagram, the controller takes the error signal of the actuator surface deflection angle and processes this signal and generate the gating signals of the power switches to feed the motor with the required power. As a result, the motor rotates at a suitable speed and specific torque to drive the ball-screw and change the actuator surface to reach the desired deflection angle [25].

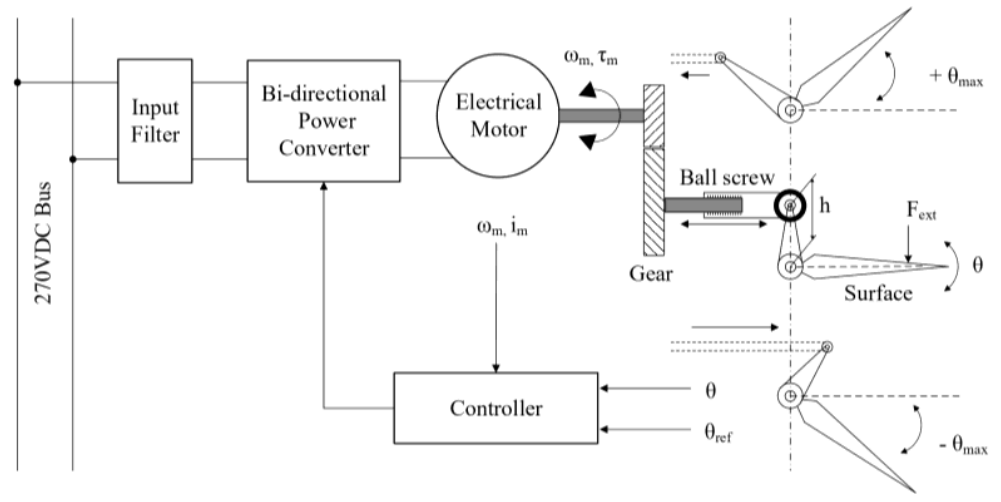

Figure 1

Electro-mechanical actuator configuration

\subsection{Electro-Hydrostatic Actuator (EHA)}

The EHA has standard hydraulic bypass valves to guarantee ease use of traditional active-standby or active-active actuator architectures. It is closely similar to conventional centralized hydraulic actuators in operating. Thus, the EHA is more suitable for primary flight control. The EHA can consume low quiescent power when operating in standby mode [26], and it is capable of performing a quick response at startup using an efficient electrical system. Moreover, EHA is more efficient than hydraulic actuators, and its efficiency is up to $70 \%$, while the efficiency of the conventional actuators is typically $50 \%$ maximum. As shown in Fig. 2, the EHA is driven by an electric motor. The reference deflection angle 
$\left(\theta_{\text {ref }}\right)$ is determined according to the desired position of the actuator surface and compared to the actual deflection angle $(\theta)$ then the error signal of the deflection angle is processed by the control unit to generate the optimal states of the power converter switches. The power converter unit regulates voltage, and current applied to the electric motor to rotate in both directions and provide a specific torque to drive the pump, thus moving the piston in the required direction. The piston movement and the arm will change the angle of the deflection of the surface to reach the desired position in both directions. The power converter is connected to the 270 VDC bus through the filter to mitigate the high-frequency harmonics generated in the system. The EHA is chosen for this study because it used not only in aerospace actuators but also in many industrial applications.

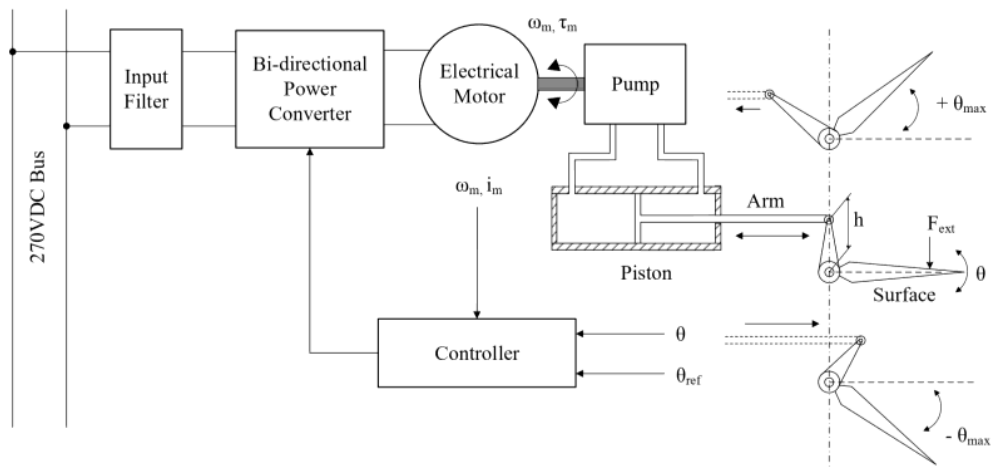

Figure 2

Electro-hydrostatic actuator configuration

\section{Transformer Rectifier Unit Control}

The on-board electric power system of modern aircraft has 400VAC variable frequency (400 - 800) $\mathrm{Hz}$ synchronous generators connected to the main $\mathrm{AC}$ bus. In order to provide a fixed 270 VDC voltage for actuators supply bus, it is important to select the power converter topology and its control technique appropriately. In aircraft applications, the Transformer Rectifier Unit (TRU) converts the AC voltage generated by the generators to a suitable DC voltage which can be used by the electrical components incorporated into the system such as an electrical actuator. This section will discuss the control of the power converter that can meet the requirements of high-performance TRU. The studied three-phase AC/DC converter topology with the proposed control scheme is shown in Fig. 3.

The converter uses six bi-directional switches. It is assumed that all switches are ideal and the characteristics of all circuit elements are linear and time-invariant. 
Assuming a balanced three-phase supply:

$$
i_{s a}(t)+i_{s b}(t)+i_{s c}(t)=0 \rightarrow i_{s c}(t)=-i_{s a}(t)-i_{s b}(t)
$$

Thus, the rectifier current $i_{r}$ :

$$
\begin{aligned}
& i_{r}=s_{a}(t) i_{s a}(t)+s_{b}(t) i_{s b}(t)+s_{c}(t) i_{s c}(t) \\
& =\left(s_{a}-s_{c}\right) i_{s a}(t)+\left(s_{b}-s_{c}\right) i_{s b}(t)
\end{aligned}
$$

where $s_{a}, s_{b}$, and $s_{c}$ are the switching states of the corresponding phases.

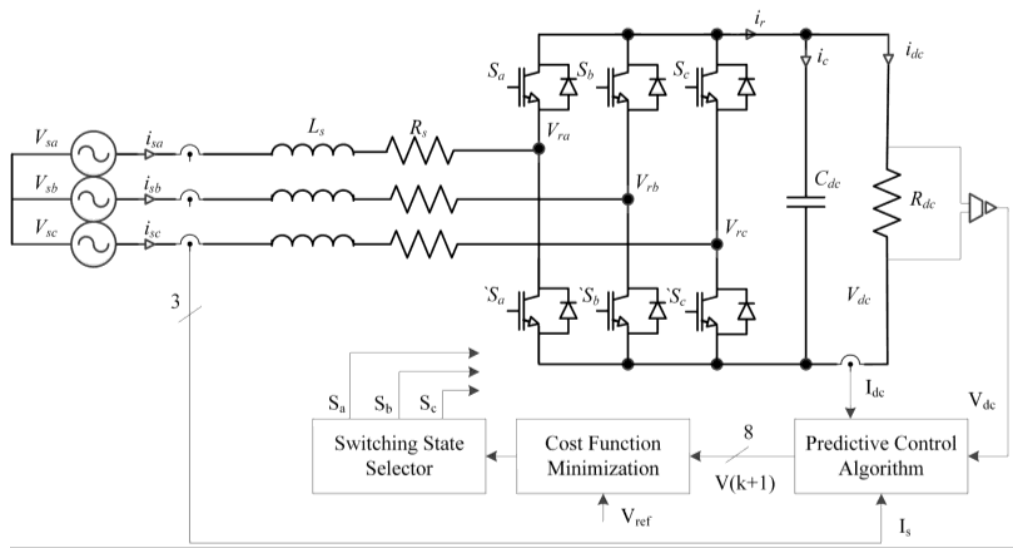

Figure 3

Three-phase voltage-source AC/DC converter

The governing equations of the system to obtain a dynamic model for the rectified voltage $V_{d c}(t)$ and the currents on the DC side can be deduced as:

$$
\begin{aligned}
& i_{c}(t)=i_{r}(t)-i_{d c}(t)=C_{d c} \frac{d v_{d c}(t)}{d t} \\
& C_{d c} \frac{d v_{d c}(t)}{d t}=\left(s_{a}-s_{c}\right) i_{s a}(t)+\left(s_{b}-s_{c}\right) i_{s b}(t)-i_{d c}(t)
\end{aligned}
$$

The predicted DC voltage $V_{d c}(k+1)$ can be calculated using the discrete-time equation as:

$$
V_{d c}(k+1)=\frac{T_{s}}{C_{d c}}\left[\left(s_{a}-s_{c}\right) i_{s a}(t)+\left(s_{b}-s_{c}\right) i_{s b}(t)-i_{d c}(k)\right]+V_{d c}(k)
$$

Where $V_{d c}(t)$ is the rectified DC bus voltage, $C_{d c}$ is the output capacitor, $V_{d c}(k)$ and $V_{d c}(k+1)$ the current and future capacitor voltages, $T_{s}$ is the sampling time, and $i_{d c}(k)$ is the load current. 
The proposed MPC algorithm for AC/DC power converter control is built as the flow chart demonstrates the main steps in Fig. 4. The predictive voltage controller must achieve the smallest voltage error with fast dynamics. So, a suitable cost function is used to measure and minimize the predicted voltage error by selecting the optimal switches states. The cost function $(g)$ considers the absolute error between the reference voltage $V_{r e f}$ and the predicted voltage $V_{d c}(k+1)$.

$g=\left|V_{r e f}-V_{d c}(k+1)\right|$

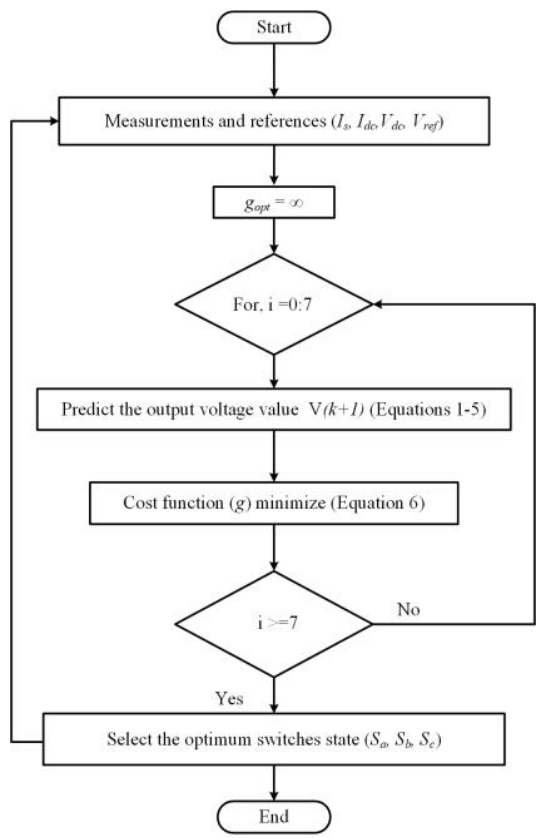

Figure 4

The predictive control algorithm of the AC/DC power converter

\section{Current Control of SRM}

There are several types of applications where the load on the SRM varies with speed over large ranges. These applications may require accurate speed control and good dynamic responses, as in aircraft actuators. In electrical actuators, the SRM is driven by the power converter to provides four quadrants operation mode, and the controller feedback signal can be the actuator surface position or motor shaft speed. During this study, the nonlinear model of SRM (6/4) is simulated, and the power converter topology is the symmetrical converter type that is controlled by predictive control techniques. 
The predictive current control uses the equivalent circuit equations of the motor model to predict the future value of the stator current. There are many methods to establish the non-linear model of SRM, such as look-up table and interpolation techniques, neural network techniques, and analytical methods. In this work, the Look-up table technique is used to find the different values of the machine inductance according to the rotor position and phases current. Therefore, the equations of the SRM can be written as [27, 28]:

$$
\begin{aligned}
& V=R_{s} I+\frac{d\{L(\theta, I) I\}}{d t}=R_{s} I+L\{\theta, I\} \frac{d I}{d t}+I \frac{d \theta}{d t} \frac{d\{L(\theta, I)\}}{d t} \\
& =R_{s} I+L\{\theta, I\} \frac{d I}{d t}+\frac{d\{L(\theta, I)\}}{d t} \omega_{m} I \\
& L\{\theta, I\} \frac{d I}{d t}=V-R_{s} I+\frac{d\{L(\theta, I)\}}{d t} \omega_{m} I
\end{aligned}
$$

where $V$ represents the phase voltage, $R_{s}$ describes phase resistance, while $L$ symbolizes a mutual inductance, $\psi=L\{\theta, I\}$ represents the flux linkage per phase according to the position of the rotor $\theta$ and phase current $I$, and $\omega_{m}$ is the motor angular speed in radians/sec.

By applying the discrete-time form, the future values of the motor phases current $I(k+1)$ can be calculated from equation (8) as follows:

$$
\begin{aligned}
& L\{\theta, I\} \frac{I(k+1)-I(k)}{d t}=V(s g)-R_{s} I+\frac{d\{L(\theta, I)\}}{d t} \omega_{m} I \\
& I(k+1)=\frac{T_{s}}{L\{\theta, I\}}\left(V(s g)-R_{s} I+\frac{d\{L(\theta, I)\}}{d t} \omega_{m} I\right)+I(k)
\end{aligned}
$$

where $V(s g)$ is voltage vector according to the switches status of the power converter, in this case, there are 27 different voltage vectors, $I(k)$ motor phases current, and $T_{s}$ symbolizes the sampling time.

In this study, the significant objective of the controller is to maintain the stator current close to the reference current, which is usually set by a speed control loop, leading to the minimization of the motor shaft torque ripples. The further objectives that will be considered in the cost function equation are a reduction of the average switching frequency and minimize the copper losses in stator windings. It is necessary for the control algorithm to produce the smallest possible values of the current error, optimize the average switching frequency, and minimize the copper losses. Therefore, the cost function is calculated for all possible voltage vectors/switches stats of the power converter, because there are three states for each phase $(+\mathrm{Vdc}, 0,-\mathrm{Vdc})$ and this study used a three-phase motor, so the possible switches stats are $3^{3}=27$. Then determine the optimal stats 
according to the controller objective function. Equation (11) represents the cost function $(\mathrm{g})$, The cost function $\mathrm{g}$ is calculated for all $\mathrm{n}=27$ different voltage vectors $\mathrm{V}_{\mathrm{g}}$ according to switching vector $\mathrm{S}_{\mathrm{g}}$, and the voltage vector that minimizes cost function $(\mathrm{g})$ will be applied to the motor phases in the next time interval. Figure 5 illustrates the flow chart that describes how the proposed current control algorithm was built.

$$
g=\left|I_{r e f}-I_{j}(k+1)\right|+\lambda_{1} \sum_{j=1}^{3}\left|I_{j}(k+1)\right|+\lambda_{2}\left|S_{g}(k+1)-S_{g}(k)\right|
$$

where $\lambda_{1}$ and $\lambda_{2}$ are the weight factors for copper losses and switching times respectively, and $1>\lambda_{1}>0$ and $1>\lambda_{2}>0$.

Generally, the three controller objectives can be adjusted in the cost function by tuning the weighting factor of each objective to reach the optimal required performance according to the application. In this study case, the weights factors were set to $\lambda 1=0.03$ and $\lambda 2=0.0025$.

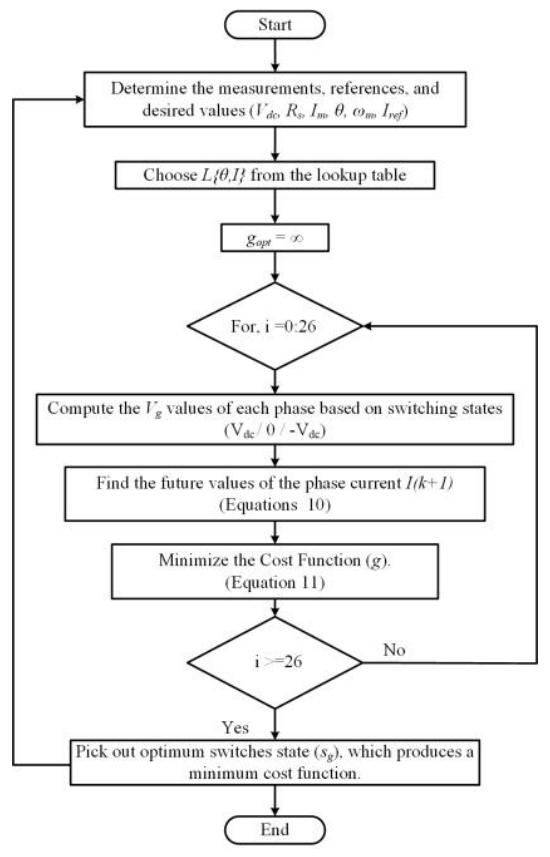

Figure 5

The proposed MPC algorithm for SRM current control

The proposed control method requires a reference current to be followed by the predicted current with the smallest possible error value. Therefore, the actual deflection angle of the actuator surface is used as a feedback signal, and the deflection angle error signal is determined by comparing the actual and desired 
deflection angle. Then, this error signal can be used as an input variable to a linear controller (PI) to produce the reference signals for the current control loop. The reference current signal can be generated using the actuator position control loop, as mentioned earlier, or by the motor speed control loop as well. The generated reference current is distributed to each phase according to the rotor position data $\theta_{m}$ in the phases commutation block. With the help of DC voltage $V_{d c}$, phase current $I(k)$, phase inductance $L\{\theta, I\}$, and motor speed $\omega_{m}$ or rotor position data $\theta_{m}$, we can determine the future values of the phase current $I(k+1)$ using equation (10). The switches state selector block will select the optimal state for all power switches of the converter according to the cost function equation that reduces the error between the calculated current and desired current to the smallest possible value, leading to reducing the error in the deflection angle of the actuator surface. To ensure the minimization of the cost function, the controller algorithm does a number of iterations equal to all possible switches state, in this study the number of iterations equals 27 as illustrated before, then it calculates the difference between the desired and the expected values, which determined using the system model, taken into account the other terms of cost function such as average switches frequency. On each iteration, the algorithm stores the switches state if it makes the cost function is smaller than the previous values. The overall configuration of the flight control surface's actuation system, including SRM and predictive control, is illustrated in Fig. 6. And The simulation model of mechanical transmission for EMA is shown in Fig. 7 [29]. This model takes into consideration, inertia, damping, the stiffness of the ball screw mechanism, stiffness of the bearing structure, and surface dynamics.

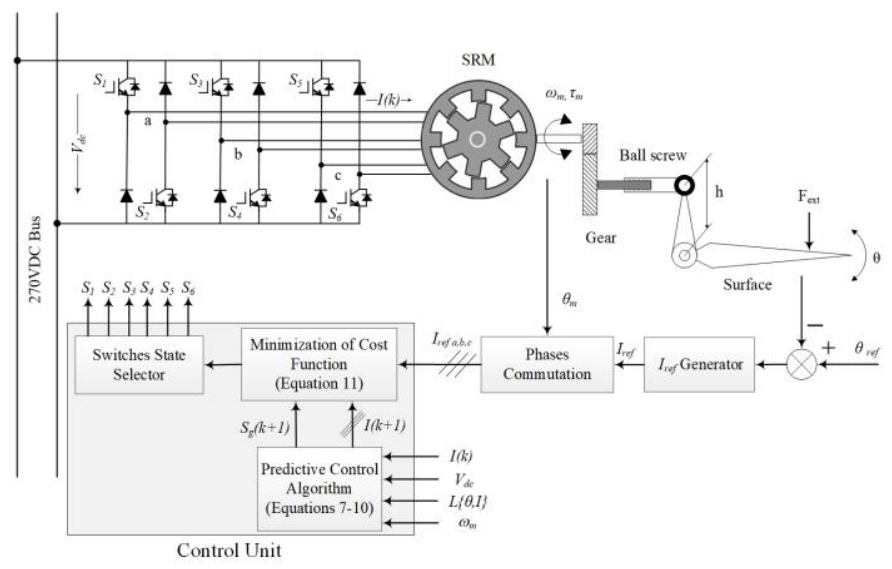

Figure 6

The configuration of the flight control surface actuation system with SRM and MPC 


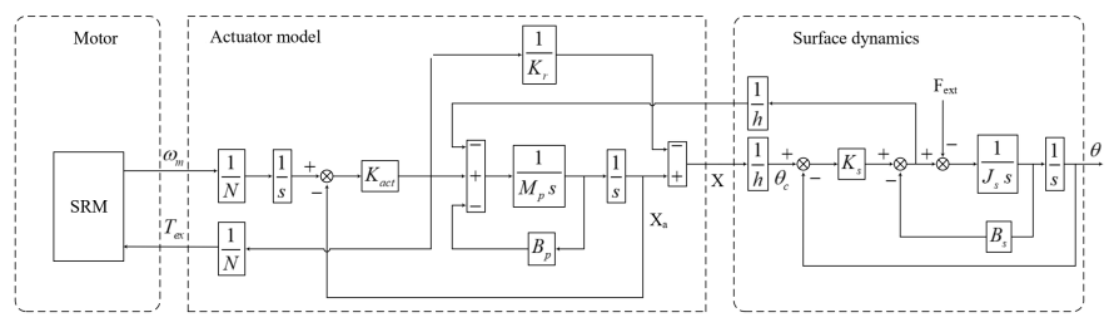

Figure 7

EMA simulation model

\section{Simulation Results and Discussions}

In this study, a $60 \mathrm{~kW} 6 / 4$ SRM model with nonlinear characteristics is simulated, and the motor's parameters listed in Table $1[30,31]$. The proposed system is simulated using PSIM software, and the MPC is programmed by C-Code.

Table 1

SRM simulation parameters

\begin{tabular}{|l|l|l|l|}
\hline Parameter & \multicolumn{1}{l}{ Values } & \multicolumn{1}{l}{ Parameter } & Values \\
\hline Rated power & $60 \mathrm{~kW}$ & Aligned inductance & $23.62 \mathrm{mH}$ \\
\hline DC supply voltage & $250 \mathrm{~V}$ & Rotation speed & $1000 \mathrm{rpm}$ \\
\hline Maximum current & $450 \mathrm{~A}$ & Moment of inertia & $0.05 \mathrm{~kg} \cdot \mathrm{m}^{2}$ \\
\hline Stator resistance & $0.05 \mathrm{Ohm}$ & Number of rotor poles & 4 \\
\hline Unaligned inductance & $0.67 \mathrm{mH}$ & Number of stator poles & 6 \\
\hline
\end{tabular}

The actuators are normally connected to the 270 VDC bus, and hence the TRU is used to provide a regulated DC voltage. In this study, the three-phase 6-switch IGBT controlled rectifier is used in TRU, and the actuator is driven by SRM with a bi-directional symmetrical converter to produce deflection in both directions. The three-phase rectifier and symmetrical converter are controlled by predictive control technique. To perform a complete simulation model of the proposed system the electric system of the Boeing-787 is taken as a study case, which considered one of the modern types of MEA. The B787 electrical power system composites from four identical channels, each channel has four buses: main $\mathrm{AC}$ bus (variable frequency), secondary AC bus, $270 \mathrm{VDC}$, and 28 VDC. A single channel of the power distribution system used in this study is shown in Fig. 8 [32]. The 270 VDC bus feeds about half of the total electric load of the aircraft, and one of the most important loads powered by this bus is the electric actuators. 


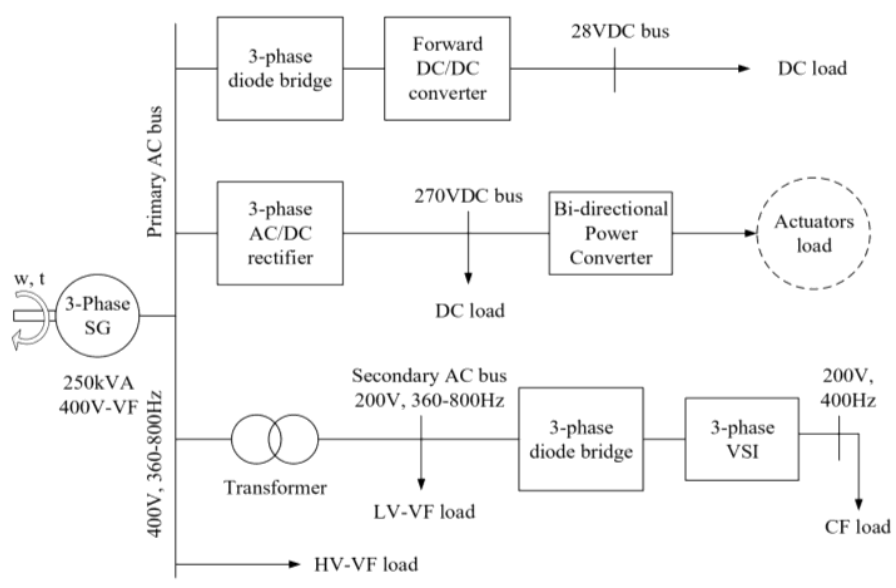

Figure 8

A single channel of MEA power distribution system

\subsection{The 270 VDC Bus Control}

The actuation system is designed to control the deflection angle of the actuator surface from the maximum positive to maximum negative values. Therefore, the power converter is controlled to act as a bi-directional converter according to the operating conditions, and the SRM will operate in four-quadrant operation mode. Continuous regulation of the DC bus helps the power converter to operate efficiently in both directions, and the predictive control of the TRU should provide a regulated DC voltage during all operating conditions. Figure 9 shows the 270 VDC voltage profile with EMA dynamic load under different operating conditions. It can be observed that voltage was regulated satisfactorily and within the allowable limits according to the aircraft standards (MIL-STD-704F) [33].

Although there are small overshoot/undershoot when the reference signal changes sharply, the voltage value remains within standard limits during a complete operating cycle, and It is better than the results were obtained in case of using the linear controller (PID) for the AC/DC converter at the same operating conditions. A comparison between the converter performance with each of the two controllers (PID, and MPC) is listed in Table 2.

Table 2

AC/DC converter performance (PID Vs MPC)

\begin{tabular}{|l|c|c|c|}
\hline \multirow{2}{*}{ Controller } & $\begin{array}{c}\text { Over/Undershoot } \\
(\%)\end{array}$ & $\begin{array}{c}\text { Ripples } \\
(\%)\end{array}$ & $\begin{array}{c}\text { Settling time } \\
(\mathrm{ms})\end{array}$ \\
\hline PID & 15.6 & 1.85 & 25 \\
MPC & 10.76 & 0.88 & 9.7 \\
\cline { 2 - 4 }
\end{tabular}




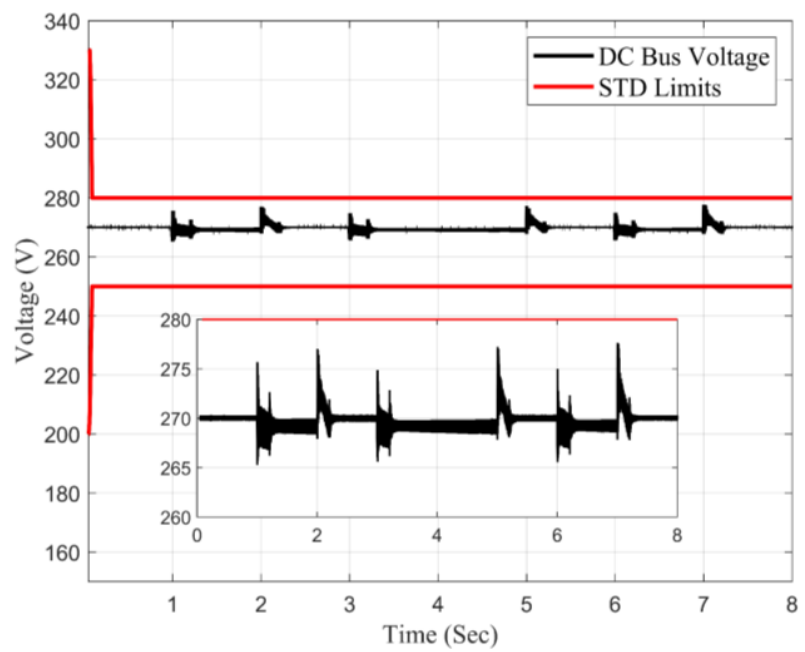

Figure 9

The 270 VDC bus voltage profile with EMA load

\subsection{SRM Control}

This part is divided into two main stages, the first one is the comparison between the torque ripples of the motor using MPC and using HCC to verify the effectiveness of MPC to control the SRM with small current and torque ripples, the obtained results verifies the ability of predictive current control algorithm to reduce the motor phase current ripples compared with traditional methods. Because of the direct effect of the phases current on motor torque, the motor torque ripples during the conduction period and motor average torque will be minimized by using a predictive current control algorithm. Table 3 summarizes the comparison between MPC and HCC at different loading conditions regarding the average torque ripples, average switching frequency, and the copper losses.

Table 3

SRM torque ripples (HCC Vs MPC)

\begin{tabular}{|c|c|c|c|}
\hline Performance & $\begin{array}{c}\text { Average } \\
\text { torque }(\%)\end{array}$ & \multicolumn{1}{c|}{$\begin{array}{c}\text { Switching } \\
\text { frequency }(\mathrm{kHz})\end{array}$} & \multicolumn{1}{c|}{$\begin{array}{c}\text { Copper } \\
\text { losses }(\mathrm{W})\end{array}$} \\
\hline HCC $($ Load torque $=10 \mathrm{Nm})$ & 17 & 6.52 & 29.2 \\
\cline { 2 - 4 } MPC $($ Load torque $=10 \mathrm{Nm})$ & 6 & 5.19 & 29.05 \\
\cline { 2 - 4 } HCC $($ Load torque $=20 \mathrm{Nm})$ & 12 & 6.15 & 54.75 \\
\cline { 2 - 4 } MPC $($ Load torque $=20 \mathrm{Nm})$ & 5 & 4.8 & 54.52 \\
\hline
\end{tabular}

The second stage is applying MPC to the aircraft actuator system, and study the overall system performance. Figure 10 shows the response of these currents, as a result of the movement of the actuator in both directions, the sequence of motor 
phases has been changed, the currents waveform in case of the positive and negative deflection angle are shown in Fig. 10-a and Fig. 10-b, respectively.
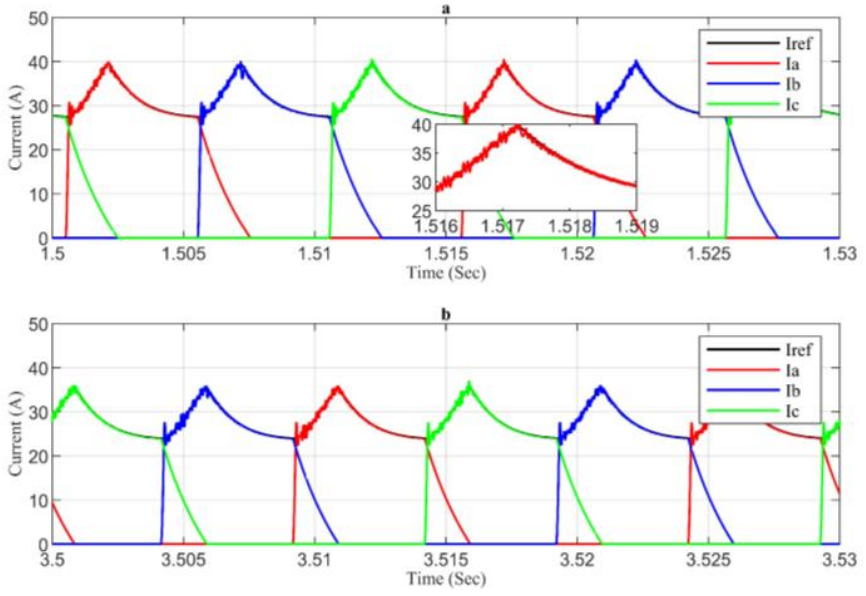

Figure 10

Motor phases current (a) positive deflection angle (b) negative deflection angle

From the obtained results we can note that the three phases current tracks the reference current signal generated from speed or position control loop in both directions with small ripples, which confirm the effectiveness of the proposed current controller algorithm.

Figure 11 shows the speed of the motor at possible different operating conditions, and the reference speed signal is set to provide the motor rotation in both directions and to give the trapezoidal shape of the actuator deflection angle. It can be seen that the actual speed tracks the reference signals in the complete operation period. Three snapshots of the motor speed profile are taken and zoomed to verify MPC performance. By zooming the speed signal, we can see the peak values of the overshoot and undershoot in both directions are about $10 \mathrm{rpm}(1 \%)$, which confirms the effectiveness of MPC in aircraft electric actuators. But it should be noted here that the MPC causes some ripples in the steady-state.

The main objective of this work is to control the deflection angle of the flight control surfaces. Therefore, the performance of the deflection angle for a complete operating period (from 0 to $\pm \theta_{\max }$ ) is shown in Fig. 12. Two snapshots of the deflection angle have been taken to show the maximum and final position of the deflection angle. As we see, the actual deflection angle follows the reference one with a small error, this error is less than $0.2^{\circ}$, which represent $0.4 \%$. These results demonstrate the possibility used of the proposed system to control the deflection angle of the flight control surfaces with satisfactory performance. 


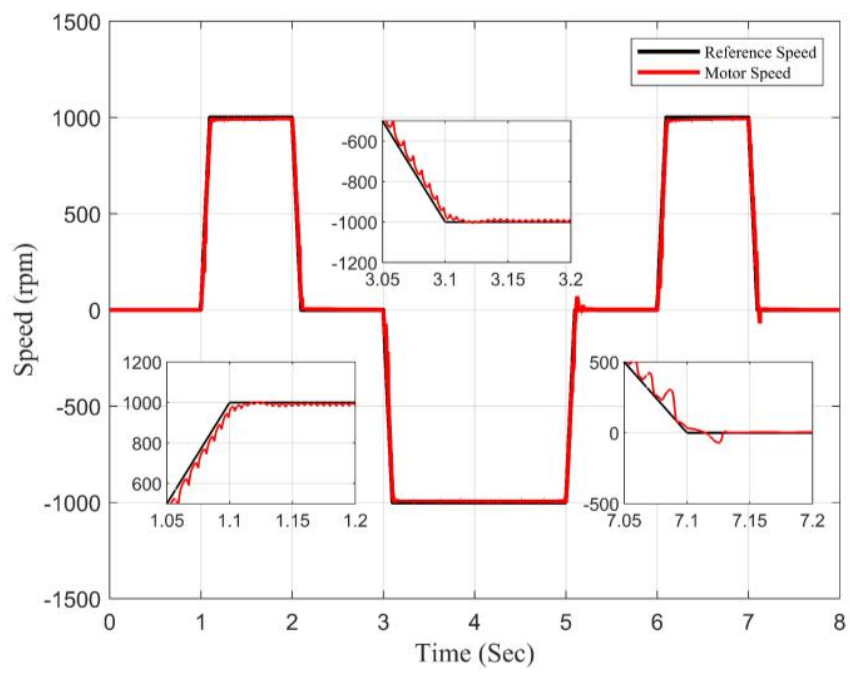

Figure 11

Motor speed performance with a zoom at different speed values

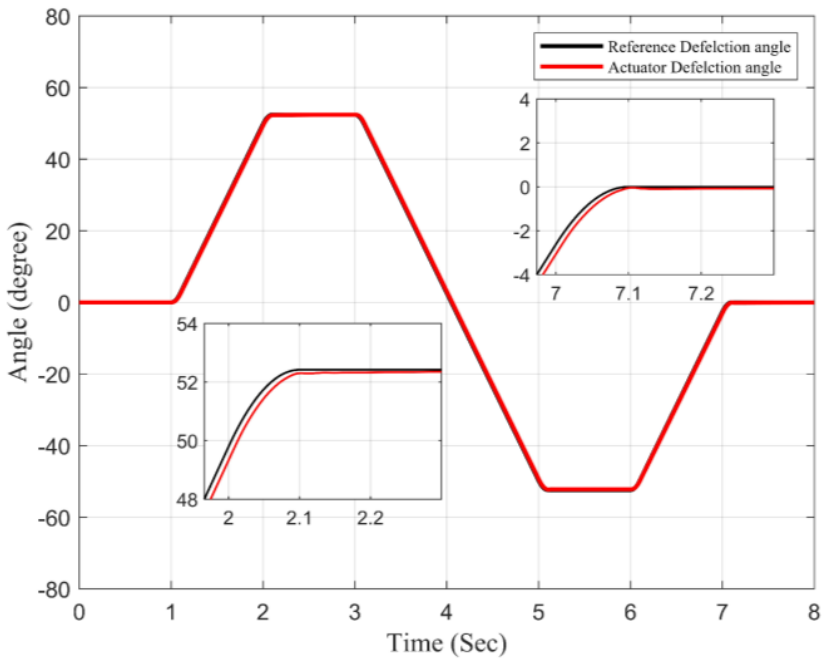

Figure 12

A complete cycle of the EMA deflection angle using MPC with a zoom at different edges

It is known that the main challenge of using SRM in many applications is the problem of torque ripples. But thanks to the predictive current control technology of the SRM proposed in this work, the torque ripples have been reduced as explained previously in Table 3 . Figure 13 shows the torque performance of the SRM during a complete cycle of the deflection angle. 


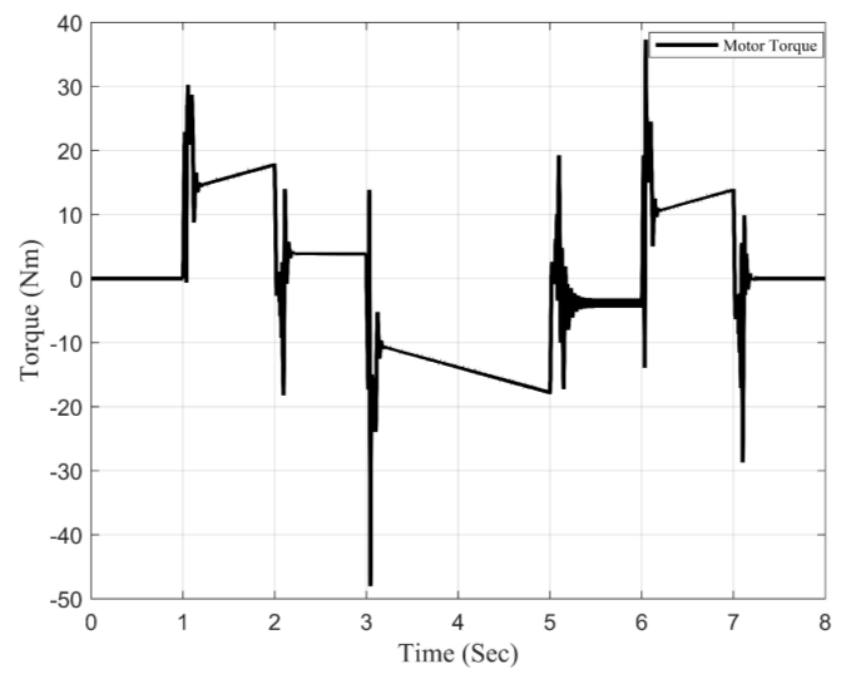

Figure 13

SRM torque for a complete cycle of the deflection angle

From the SRM torque diagram, we can observe that the torque of the motor increases when the deflection angle of the actuator surface increases due to the external forces that affect the surface as the wind force. Then the torque becomes constant when the surface reaches its new position. Next, the same behavior occurs in the negative period of the deflection angle during the actuator surface return to zero position. Finally, the torque returns to zero again when the surface reaches its zero position at the end of the cycle. This diagram also shows that the MPC can effectively control the SRM with small values of torque ripples to drive the flight control surface actuators.

\section{Conclusions}

In this study, the authors built a simulation model for the SRM-based flight control actuator for modern civil aircraft applications. The electric motor control unit is designed using predictive control technique, and the MPC was also used for TRU controller to regulate the 270 VDC bus for actuators supply. With the help of MPC, TRU provides a fixed DC voltage under the actuator dynamic load effects at transient and steady-state operating conditions. Using the predictive current control for SRM, the motor speed, and the flight control surface deflection accurately track the desired signals. The proposed control algorithm produces a small overshoot/undershoot in the motor speed about $\pm 10 \mathrm{rpm}(1 \%)$ with small ripples in the motor torque, and the maximum error in the deflection angle around $0.4 \%$. The obtained results demonstrate the effectiveness of the proposed system in aircraft electrical actuators. These results confirm that the MPC techniques provide a good response of the motor speed controller, with acceptable torque ripples values in all operating conditions, and produce the desired deflection angle 
for flight control surfaces in both directions accurately. Of the above, we can conclude that the SRM controlled by MPC can efficiently drive the flight control surfaces actuators, for civil aircraft applications.

\section{References}

[1] Ian Moir and Allan Seabridge, "Aircraft systems: mechanical, electrical, and avionics subsystems integration," $3^{\text {rd }}$ ed., John Wiley\&Sons, 2008

[2] A. Eid, M. Abdel-Salam, H. El-Kishky, and T. El-Mohandes "Simulation and transient analysis of conventional and advanced aircraft electric power systems with harmonics mitigation," Electric Power Systems Research, Vol. 79, No. 4, pp. 660-668, 2009

[3] Reyad Abdel-Fadil, Ahmad Eid, and Mazen Abdel-Salam, "Electrical distribution power systems of modern civil aircrafts," in $2^{\text {nd }}$ International Conference on Energy Systems and Technologies, Cairo, Egypt, pp. 201210, 2013

[4] D. R. Trainer and C. R. Whitley, "Electric actuation - power quality management of aerospace flight control systems," in International Conference on Power Electronics, Machines and Drives, Sante Fe, NM, USA, pp. 229-234, 2002

[5] Richard M. Crowder, "Electrically powered actuation for civil aircraft," in IEE Colloquium on Actuator Technology: Current Practice and New Developments, pp. 5/1-5/3, 1996

[6] K. P. Louganski, "Modeling and analysis of a dc power distribution system in $21^{\text {st }}$ Century airlifters," M.Sc., Virginia Polytechnic Institute and State University, 1999

[7] R. Abdel-Fadil, A. Eid, and M. Abdel-Salam, "Fuzzy Logic Control of Modern Aircraft Actuators," in $3^{\text {rd }}$ International Conference on Energy Systems and Technologies, Cairo, Egypt, pp. 149-158, 2015

[8] R. Abdel-Fadil, A. Eid, and M. Abdel-Salam, "Control and Performance Investigation of Modern Civil Aircraft Actuators using Model Predictive Control," in The $17^{\text {th }}$ International Middle East Power Systems Conference (MEPCON'15), Cairo, Egypt, 2015

[9] T. J. E. Miller, "Electronic Control of Switched Reluctance Machines," First Edition, Newnes, Oxford, UK, 2001

[10] K. Vijayakumar. R. Karthikeyan, S. Paramasivam. R. Arumugam, and K. N. Srinivas, "Switched Reluctance Motor Modeling, Design, Simulation, and Analysis: A Comprehensive Review," IEEE Transactions on Magnetics, Vol. 44, No. 12, pp. 4605-4617, 2008

[11] R. Krishnan, "Switched Reluctance Motor Drives :Modeling, Simulation, Analysis, Design, and Applications”, $1^{\text {st }}$ ed., CRC Press, Germany, 2001 
[12] R. Abdel-Fadil and L. Számel, "State of the Art of Switched Reluctance Motor Drives and Control Techniques," in Twentieth International Middle East Power Systems Conference, Cairo, Egypt, pp. 779-784, 2018

[13] Patricio Cortés, Marian P. Kazmierkowski, Ralph M. Kennel, Daniel E. Quevedo, and José Rodríguez, "Predictive control in power electronics and drives," IEEE Transactions on Industrial Electronics, Vol. 55, No. 12, pp. 4312-4324, 2008

[14] Jose Rodriguez and Patricio Cortes, "Predictive control of power converters and electrical drives," $11^{\text {st }}$ ed., John Wiley\&Sons, Ltd, US, 2012

[15] R. Haber, R. Bars, and U. Schmitz, "Predictive control in process engineering, from the basics to the applications," $1^{\text {st }}$ ed., WILEY-VCH Verlag GmbH\&Co, Germany 2011

[16] G. Abbas, U. Farooq, and J. Gu and M. U. Asad, "Constrained model based predictive controller for a high-frequency low-power DC-DC buck converter," International Journal on Electrical Engineering and Informatics, Vol. 5, No. 3, pp. 316-339, 2013

[17] L. Tarisciotti, P. Zanchetta, A. Watson, J. C. Clare, M. Degano, and S. Bifaretti, "Modulated model predictive control for a three-phase active rectifier,", IEEE Transactions on Industry Applications, Vol. 51, No. 2, pp. 1610-1620, 2015

[18] R. Abdel-Fadil and L. Számel, "Enhancement Of the Switched Reluctance Motor Performance for Electric Vehicles Applications Using Predictive Current Control," in 2018 International IEEE Conference and Workshop in Óbuda on Electrical and Power Engineering (CANDO-EPE), Budapest, Hungary, pp. 195-200, 2018

[19] S. Vazquez, J. Rodriguez, M. Rivera, L. G. Franquelo, and M. Norambuena, "Model Predictive Control for Power Converters and Drives: Advances and Trends," IEEE Transactions on Industrial Electronics, Vol. 64, No. 2, pp. 935-947, 2017

[20] A. Eid, R. Abdel-Fadil, and M. Abdel-Salam, "Performance and Power Quality Improvements of MEA Power Distribution Systems using Model Predictive Control," International Review of Aerospace Engineering, Vol. 10, No. 1, pp. 31-40, 2017

[21] A. Árpád Takács, Levente Kovács, Imre J. Rudas, Radu-Emil Precup, and Tamás Haidegger, "Models for Force Control in Telesurgical Robot Systems," Acta Polytechnica Hungarica, Vol. 12, No. 8, pp. 95-114, 2015

[22] K. K. Tan, S. Zhao and J.-X. Xu, "Online automatic tuning of a proportional integral derivative controller based on an iterative learning control approach," IET Control Theory Appl., Vol. 1, No. 1, pp. 90-96, 2007 
[23] Rafael Pedro Alvarez Gil1, Zsolt Csaba Johanyák, and Tamás Kovács, "Surrogate Model based Optimization of Traffic Lights Cycles and Green Period Ratios using Microscopic Simulation and Fuzzy Rule Interpolation," International Journal of Artificial Intelligence, Vol. 16, No. 1, pp. 20-40, 2018

[24] S. Preitl, R. Precup, Z. Preitl, S. Vaivoda, S. Kilyeni, and József K. Tar, "Iterative Feedback And Learning Control. Servo Systems Applications," IFAC Workshop ICPS'07, Cluj-Napoca, Romania, pp. 16-27, 2007

[25] X. Du, R. Dixon, R. M. Goodall, and A. C. Zolotas, "Modelling and control of a high redundancy actuator,", Mechatronics, Vol. 20, No. 1, pp. 102-112, 2010

[26] C. A. Constantino, L. S. Góes, and F. J. Moreira, "High frequency modeling of a hydraulic actuation flight control system," in $9^{\text {th }}$ Brazilian Conference on Dynamics Control and their Applications, Serra Negra, Brazil, pp. 1080-1090, 2011

[27] C. Li, G. Wang, Yan Li, and Aide Xu, "An improved finite-state predictive torque control for switched reluctance motor drive," IET Electric Power Applications, Vol. 12, No. 1, pp. 144-151, 2018

[28] V. Jambulingam, "Mathematical Modeling and Simulation of Switched Reluctance Motor," International Journal for Research in Applied Science\&Engineering Technology, Vol. 4, No. VI, pp. 441-446, 2016

[29] V. B. Blaignan and V. A. Skormin, "Stiffness enhancement of flight control actuator," IEEE Transaction on Aerospace and Electronic Systems, Vol. 29, No. 2, pp. 380-390, 1993

[30] C. Li, G. Wang, Y. Fan, and Yan Li, "Adaptive RBF Neural Network Controller Design for SRM Drives," in $35^{\text {th }}$ Chinese Control Conference, Chengdu, China, pp. 6092-6097, 2016

[31] N. Saha, and S. Panda, "Speed control with torque ripple reduction of switched reluctance motor by Hybrid Many Optimizing Liaison Gravitational Search technique," Engineering Science and Technology, an International Journal, Vol. 20, No. 3, pp. 909-921, 2017

[32] R. Abdel-Fadil, A. Eid, and M. Abdel-Salam, "Fuzzy logic control of modern aircraft electrical power system during transient and steady-state operating conditions," in IEEE International Conference on Power Electronics, Drives and Energy Systems, Mumbai, India, pp. 1-6, 2014

[33] Navy-AS: "Aircraft electric power characteristics (MIL-STD-704F)," Department of defense-USA, 2013 